\title{
INFLUÊNCIA DO TEMPO DE PERMANÊNCIA DOS OVOS DE AVESTRUZES NO NINHO SOBRE A TAXA DE ECLOSÃO
}

\author{
Nadia Nobrega Valdo, Leticia Jalloul Guimarães, Lilian Francisco Arantes de Souza, Sheila Merlo Garcia \\ Universidade do Oeste Paulista - UNOESTE, Presidente Prudente, SP. E-Mail: sheila@unoeste.br.
}

\begin{abstract}
RESUMO
O objetivo do experimento foi avaliar se o tempo de permanência dos ovos no ninho afeta a qualidade do ovo a ser incubado interferindo na taxa de eclosão. Utilizaram-se 34 ovos divididos em blocos inteiramente casualizados. A coleta dos ovos foi realizada em dois períodos, manhã (tratamento 1) e madrugada (tratamento 2). Os parâmetros de qualidade dos ovos foram avaliados por meio do peso dos ovos nos dias 0 e 39 de incubação (g), índice de perda de peso do ovo (\%), taxa de fertilidade (\%), eclodibilidade (\%) e mortalidade (\%). Os resultados obtidos mostram que não houve diferença significativa em nenhuma das variáveis analisadas. Dessa forma, pode-se concluir que o tempo de permanência no ninho não influência na taxa de eclosão dos ovos, uma vez que o baixo índice de eclodibilidade possa estar relacionado a problemas durante o manejo de incubação, genéticos ou nutricionais.
\end{abstract}

Palavras-chave: incubação; qualidade do ovo; eclodibilidade; ninho; avestruz.

\section{INFLUENCE OF DWELL TIME OSTRICHES OF EGGS IN NEST ON OUTBREAK RATE}

\begin{abstract}
The experiment's goal was to assess whether the pace of Permanence of non- nest eggs affects egg quality of a being incubated interfering with the hatching rate. They used 34 eggs divided into randomized blocks. The collection of eggs was carried out in two periods, morning (treatment 1) and dawn (Treatment 2). The quality parameters of eggs Were evaluated by weight Half of eggs On days 0 and 39 of incubation $(\mathrm{g})$ loss rate of egg weight (\%), fertility rate (\%), hatchability (\%) and mortality (\%). The obtained results show there was no significant difference in any of the analyzed variables. Thus, may be concluded that the rate of permanence without nest not influence the hatching rate of the eggs, once low hatchability rate may be related a problem during the hatchery management, genetic or nutritional.
\end{abstract}

Keywords: incubation; egg quality; hatchability; nest; ostrich.

\section{INTRODUÇÃO}

No Brasil a estrutiocultura iniciou-se a pouco mais de 21 anos, com a importação de diversas matrizes e filhotes. Entretanto, o início da atividade no país foi marcado por perdas consideráveis de ovos e filhotes, devido à falta de definição dos parâmetros de incubação (VAN SCHALKWYK et al., 1996).

Dessa forma, para elevar os índices como eclodibilidade, alguns padrões da incubação devem ser observados, tais como o tempo de coleta do ovo no ninho, qualidade da casca, o manejo do incubatório, as condições de incubação e o funcionamento adequado dos equipamentos (BRAMWELL, 2002).
Como já é sabido, a variação de tempo e exposição dos ovos a fatores ambientais são condições que afetam a qualidade dos ovos, a eficiência durante a incubação e consequentemente $\mathrm{o}$ desenvolvimento do embrião.

Desta maneira, a vistoria dos ninhos e coleta dos ovos deve acontecer de duas a três vezes ao dia, e coincidir com o fornecimento do concentrado ou volumoso aos animais, evitando maior exposição do ovo ao meio ambiente (VAN SCHALKWYK et al., 1999).

Como são poucos os estudos a respeito do manejo e do monitoramento dos ovos antes e durante a incubação, é importante e oportuno realizar pesquisas nessa área. Assim, o objetivo 
deste experimento foi avaliar se o tempo de permanência dos ovos no ninho afeta a qualidade do ovo a ser incubado interferindo na taxa de eclosão.

\section{METODOLOGIA}

O experimento foi conduzido no setor de incubação no Centro Zootécnico da Universidade do Oeste Paulista/UNOESTE em Presidente Prudente/SP. A localização da área experimental está definida pelas coordenadas geográficas: $22^{\circ} 06^{\prime} 40^{\prime \prime}$ Latitude Sul e $51^{\circ} 27^{\prime} 71^{\prime \prime}$ Longitude Oeste de Greenwich, com altitude média de 383 metros. O clima da região, segundo a classificação de Köppen, é do tipo Cwa, com temperaturas médias anuais de $25 \circ \mathrm{C}$ e regime pluvial caracterizado por dois períodos distintos, um chuvoso de outubro a março e outro de baixa precipitação pluvial de abril a setembro.

Para a realização do experimento, foi utilizada uma incubadora da marca PREMIUM ECOLÓGICA LTDA, modelo IP 30, com capacidade para 30 ovos, controle eletrônico de temperatura, viragem automática dos ovos de 4 em 4 horas, circulação forçada de ar e termômetro de precisão. Os ovos foram incubados horizontalmente em duas bandejas para 15 ovos em cada.

A coleta dos ovos foi realizada em dois momentos, manhã (tratamento 1): logo após a postura e madrugada (tratamento 2): ovos oriundos da postura realizada no período da tarde do dia anterior. Os ovos botados no período da manhã eram imediatamente retirados do ninho e encaminhados ao incubatório. Entretanto, os ovos oriundos de fêmeas que realizavam a postura no final da tarde, eram retirados do ninho somente no dia seguinte, por volta das $5 \mathrm{~h} 00$, antes do inicio da postura da manhã. O transporte dos ovos até o incubatório era realizado em caixas apropriadas de maneira a assegurar a integridade dos mesmos. Ao chegar no incubatório os ovos eram encaminhados a sala de recepção, onde imediatamente passavam por processo de higienização e posteriormente desinfecção realizada com sanizante (a base de sulfato hidrogenado de potássio, dodecil benzeno fulfonato de sódio, monopersulfato de potássio, sulfato de potássio, ácido sulfâmico), dissolvido em água quente, na proporção de $1 \mathrm{~kg}$ para $280 \mathrm{~L}$, em seguida eram identificados com numeração, data e hora da coleta, além disso, eram pesados em balanças digitais com capacidade para $5 \mathrm{~kg}$ e logo após realizava-se a identificação da câmara de ar a partir do método de ovoscopia. Ao final, os ovos eram estocados durante 7 dias, com inclinação de 45 o e câmara de ar voltada para cima.

O delineamento experimental foi realizado em blocos inteiramente casualizados. Os ovos foram posicionados aleatoriamente nas incubadoras, conforme o espaço disponível, onde permaneceram por aproximadamente 38 dias, até o dia do nascimento.

Durante o processo de incubação, foram realizadas mais três pesagens e ovoscopias (aos 14, 21 e 39 dias pós-postura), nas quais ovos inférteis, contaminados e/ou com mortalidade embrionária foram descartados na segunda e na terceira ovoscopia (14 e 21 dias).

A perda de peso dos ovos foi calculada a partir do Índice de Perda de Peso (PP), que é dado pela diferença de peso em porcentagem entre a postura e o momento da ovoscopia em questão. A porcentagem de perda de peso total foi calculada usando-se a equação, [(peso inicial do ovo - peso do ovo com 38 dias) / peso inicial do ovo] x 100.

Os dados referentes aos pesos dos ovos e perda de umidade foram analisados por meio do teste $\mathrm{t}$ de Student. Os dados referentes á fertilidade, eclodibilidade e mortalidade foram analisados por meio do teste exato de Fisher. As análises foram realizadas no programa BioEstat 5.3 utilizando nível de significância de 5\% $(p<0,05)$.

\section{RESULTADOS}

Não houve efeito significativo $(p>0,05)$ entre os tratamentos, sobre os índices de peso médio dos ovos e perda de peso durante a incubação (Tabela 1), uma vez, o tempo de permanência do ovo no ninho não interfere nos parâmetros analisados. Todavia, quanto maior o tempo de exposição do ovo no ninho, maior a adesão de sujeiras e microrganismos na superfície da casca dos ovos, provindos do ambiente, o que pode acarretar em contaminação dos mesmos, podendo causar possíveis alterações sobre a perda de peso dos ovos, devido à penetração de bactérias aeróbicas e outros microrganismos para o interior dos ovos, acarretando em produção de gases e consequentemente influência sobre a perda de peso durante a incubação. 
Tabela 1. Peso médio e desvio padrão dos ovos no dia da incubação (Peso dia $0, \mathrm{~g}$ ), peso médio dos ovos aos 39 dias de incubação (Peso dia 39, g) e perda de peso dos ovos durante a incubação (Perda, \%).

\begin{tabular}{lccc}
\hline & \multicolumn{2}{c}{ Períodos de coleta } & \multirow{2}{*}{ Valor de p } \\
\cline { 1 - 2 } & Manhã (1) & Madrugada (2) & \\
\hline Peso dia 0 & $1494,38 \pm 102,50$ & $1519,89 \pm 102,04$ & 0,2365 \\
Peso dia 39 & $1283,94 \pm 166,85$ & $1311,83 \pm 96,71$ & 0,2813 \\
Perda & $14,36 \pm 6,82$ & $13,70 \pm 2,13$ & 0,3569 \\
\hline
\end{tabular}

Significativo quando $p<0,05$.

Nos resultados apresentados na tabela 2, referentes aos percentuais de fertilidade, eclodibilidade e mortalidade, não foram detectadas diferenças estatísticas entre os tratamentos $(p>0,05)$, o que evidencia que não houve diferença entre o menor e maior tempo de permanência do ovo no ninho no período póspostura. Entretanto, observou-se maior taxa de fertilidade para os ovos do tratamento $2 \mathrm{em}$ relação ao tratamento 1 . Porém, sabe-se que o tempo de exposição dos ovos aos fatores climáticos e ambientais não influência na sua taxa de fertilidade, visto que a fertilidade de um ovo é determinada através da capacidade de cobertura e fecundidade das matrizes. Observou-se ainda, maior porcentagem de eclosão dos ovos coletados logo após a postura em relação aos ovos coletados no dia seguinte a postura, esse resultado pode estar relacionado à menor exposição desses ovos as condições do meio ambiente e consequentemente menor contaminação por microrganismos que podem ser um dos principais causadores de mortalidade embrionária, entretanto, não houve diferenças estatísticas, para confirmar tal hipótese.

Tabela .2. Fertilidade, eclodibilidade e mortalidade (\%) dos ovos coletados em diferentes períodos póspostura.

\begin{tabular}{lccc}
\hline & \multicolumn{2}{c}{ Períodos de coleta } & \multirow{2}{*}{ Valor de p } \\
\hline Fertilidade & Manhã (1) & Madrugada (2) & \\
Eclodibilidade & 68,75 & 94,44 & 0,0644 \\
Mortalidade & 27,27 & 17,65 & 0,4390 \\
\hline
\end{tabular}

Significativo quando $p<0,05$.

\section{DISCUSSÃO}

Segundo os resultados apresentados na Tabela 1, os ovos em ambos os tratamentos apresentaram peso médio e perda de peso semelhantes. Nesse caso, os resultados assemelham-se aos encontrados na literatura. De acordo com Nahm (2001), a desidratação dos ovos pode variar de $12 \%$ a $18 \%$. Entretanto, em estudos realizados no Brasil, Carrer e Kornfeld (2001), encontraram valores para a perda de água dos ovos de avestruzes entre 14 e 16\%. Já Gonzalez et al., (1999) afirma que para o ovo ter um bom desenvolvimento embrionário deve perder, em média, $15 \%$ de sua massa inicial, o que justifica a necessidade do acompanhamento da variação de seu peso.

De acordo com os resultados observados na Tabela 2, nota-se alta taxa de mortalidade embrionária. Segundo Carrer et al. (2004) a maior incidência de mortalidade é observada nos terços (inicial e final) porém essas ocorrências estão relacionadas a aspectos ligados ao manejo de incubação e/ou genéticos, afirmando que essas ocorrências não são sinais de problemas nutricionais. Contudo, o mesmo autor, afirma que uma grave deficiência de nutrientes, principalmente de algumas vitaminas ou de excesso de toxinas circulantes e carência de fornecimento de oxigênio no processo de troca gasosa da incubadora podem ocasionar mortalidade no segundo terço da fase embrionária. Entretanto, Hicks-Alldredge (1998), afirma que a nutrição inadequada das matrizes reprodutoras ou toxinas presentes na alimentação dos mesmos, também pode contribuir para o aumento desse problema.

\section{CONCLUSÃO}

Não foram detectadas diferenças estatísticas entre os tratamentos em nenhuma das variáveis analisadas o que evidencia que o tempo de permanência no ninho não influencia na taxa de eclosão dos ovos, uma vez que o baixo índice de eclodibilidade possa estar relacionado a 
problemas durante o manejo de incubação,

\section{REFERÊNCIAS}

BRAMWELL, R.K. Egg shell mottling and hatchability. 2002. Disponível em: <http://www.thepoultrysite.com/FeaturedArticle /FATopic.asp?AREA=Incubation\&Display=28 >. Acesso em: 06 fev. 2016.

CARRER, C. C; KORNFELD, M. E. Taxa de fertilidade e índice de perda de peso de ovos de avestruzes (Struthio camelus), sob incubação artificial. In: CONGRESSO BRASILEIRO DE ESTRUTIOCULTURA, 2001. Campinas. Anais... Campinas: Associação de Criadores de Avestruzes do Brasil, 2001. 1CD-ROM.

CARRER, C. C. et al. A criação de avestruzes no Brasil. Guia completo de A a Z. In: Brasil Ostrich ${ }^{\circledR}$. Pirassununga, 2004. p. 134.

GONZALEZ, A. et al. Factors affecting ostrich egg hatchability. Poultry science, v.78, n.9, p.12571262, 1999. Disponível em: <http://ps.oxfordjournals.org/content/78/9/1257 .short>. Acesso em: 04 mar. 2016.

HICKS-ALLDREDGE, K. Ratite Reproduction. Veterinary Clinics of North America: Food Animal Practice, v.14, n.3, p. 437-453, 1998. https://doi.org/10.1016/S0749-0720(15)30230-9

NAHM, K. H. Effects of storage length and weight loss during incubation on the hatchability of genéticos ou nutricionais.

ostrich eggs (Struthio camuelus). Poultry science, v. 80 , n. 12, p. 1667-1670, 2001. Disponível em: <http://ps.oxfordjournals.org/content/80/12/166 7.short >. Acesso em: 03 mar. 2016.

VAN SCHALKWYK, S. J. et al. Repeatability and phenotypic correlations for body weight and reproduction in commercial ostrich breeding pairs. British Poultry Science, v.37, n.5, p.953962, 1996. Disponível em: <http://www.tandfonline.com/doi/abs/10.1080/ 00071669608417926>. Acesso em: 05 fev. 2016.

VAN SCHALKWYK, S. J; BRAND, Z; CLOETE, S. W. P; BROWN, C. R. Effects of time collection and preincubation treatment on blastoderm development and embryonic mortality in ostrich embryos. South African Journal of Animal Science, v.29, n.3, p.154-163, 1999.

Recebido para publicação em 16/12/2016

Revisado em 16/02/2017

Aceito em 27/03/2017 